\section{Intersections}

Canadian Journal of Music

Revue canadienne de musique
Intersections CANADIAN JOURAL OF MUSIC
REVUE CANADIENEE DE MUSIOUH

\title{
Examining a Canadian Jazz Icon: Pitch-Class Hierarchy in Some Representative Examples of Kenny Wheeler
}

\section{Scott Cook}

Volume 32, numéro 1-2, 2012

URI : https://id.erudit.org/iderudit/1018581ar

DOI : https://doi.org/10.7202/1018581ar

Aller au sommaire du numéro

\section{Éditeur(s)}

Canadian University Music Society / Société de musique des universités canadiennes

ISSN

1911-0146 (imprimé)

1918-512X (numérique)

Découvrir la revue

Citer cet article

Cook, S. (2012). Examining a Canadian Jazz Icon: Pitch-Class Hierarchy in Some Representative Examples of Kenny Wheeler. Intersections, 32(1-2), 117-141.

https://doi.org/10.7202/1018581ar
Résumé de l'article

Cet article examine quelques pièces représentatives de l'oeuvre du trompettiste et compositeur canadien Kenny Wheeler. Bien que son travail soit ancré dans la tradition jazz, les compositions de Wheeler s'en distancient souvent. Ses enchaînements d'accords, par exemple, sont parfois remarquablement chromatiques et souvent non-diatoniques. De plus, il élimine souvent les accords de septième majeurs et mineurs, ce qui diminue le sens de la fonction harmonique traditionnelle. Toutefois, ses mélodies tendent à favoriser des relations de plus longue portée en mettant l'emphase sur certains ensembles de hauteurs plus que sur d'autres. En contraste avec l'approche traditionnelle de l'analyse harmonique des pièces de jazz, l'objectif principal de cet article est de montrer qu'il est possible de concevoir une continuité au sein d'enchaînements harmoniques moins conventionnels, lorsque l'on adopte une approche analytique allant du haut vers le bas, et qui en fait donne priorité à la mélodie.
Copyright @ Canadian University Music Society / Société de musique des universités canadiennes, 2013
Ce document est protégé par la loi sur le droit d'auteur. L'utilisation des services d’Érudit (y compris la reproduction) est assujettie à sa politique d'utilisation que vous pouvez consulter en ligne.

https://apropos.erudit.org/fr/usagers/politique-dutilisation/ 


\title{
EXAMINING A CANADIAN JAZZ ICON: PITCH-CLASS HIERARCHY IN SOME REPRESENTATIVE EXAMPLES OF KENNY WHEELER
}

\author{
Scott Cook
}

Jazz trumpeter and composer Kenny Wheeler has had a long and productive career. A contemporary of such legends as Bill Evans, ${ }^{1}$ Wheeler remains an active performer and composer. Wheeler has released more than thirty albums-at the time of writing, his most recent release was in February 2013. Throughout his career, Wheeler has been a sideman for jazz greats such as Anthony Braxton and Dave Holland. When he is acting as a composer, his albums tend to exclude the common-practice standards in favour of original material, and his recordings continuously feature all-star ensembles, including Keith Jarrett, Lee Konitz, Dave Holland, Bill Frisell, John Abercrombie, and Jack DeJohnette, among others. Simply put, Wheeler's significance in the professional jazz community seems undeniable. ${ }^{2}$

Wheeler was born in Toronto in 1930 and raised in St. Catharines, Ontario. The son of a trombonist, Wheeler began playing the cornet at the age of twelve. A student of Toronto's Royal Conservatory, Wheeler emigrated from Canada in 1952 on a bit of a whim. Wheeler knew that he "wanted to go somewhere" but avoided the United States out of fear of being drafted to fight in the Korean War (Hum 2011). He considered Cuba and Brazil, but opted for England on account of the language.

Once overseas, Wheeler began performing in British swing and dance bands. In 1959, he was recruited by Johnny Dankworth - a leading figure in the UK jazz scene at that time-and by the early 1970s Wheeler had become, and continues to be, one of the most highly regarded jazz musicians in Europe. As a result, many Europeans consider Wheeler one of their own. ${ }^{3}$

Despite these achievements, Wheeler's music remains relatively unknown to the common jazz practitioner. For instance, Wheeler is not often mentioned

1 The Evans album entitled Quintessence (1976, Fantasy) includes a recording of the Wheeler tune "Sweet Dulcinea Blue."

2 Wheeler is also an active music educator and has been a faculty member at the Canadian Banff Workshop.

3 In their book Jazz, DeVeaux and Giddins $(2009,241)$ provide a short list of accomplished musicians who have advanced the international jazz sound. This list includes, among others, the

"English trumpeter" Kenny Wheeler. See also Eyles 2003. 
in jazz history texts or anthologies, ${ }^{4}$ and his compositions tend to be excluded from the commonly circulated jazz "real" books. And compared to other Canadian jazz icons, such as Oscar Petersen or Maynard Ferguson, Wheeler's music tends to receive greater critical attention than popular. One reason for this perspective might be Wheeler's exclusively original output, which could alienate jazz fans who are searching for another rendition of their favourite standard. Another rationale might have to do, at least in part, with Wheeler's more "contemporary"-and perhaps less accessible-sound. Wheeler's melodies, for instance, are often rhythmically complex and highly syncopated, and they contradict traditional formal "breaks" or designs. His chord successions are, at times, non-functional and can be highly chromatic. His tunes do not often make use of traditional cadence formulas and rarely use dominantseventh chords. Albeit unique, in fact Wheeler's relatively non-traditional jazz writing can make his music challenging to listeners, performers, and analysts alike.

Jazz analysis generally focuses on chords and assumes that harmony provides the basis of jazz theory (Martin 1996b, 6). The most common approach to analyzing jazz chords is chord-scale theory, which, generally speaking, maps the chords that appear on lead sheets onto scales of which those chords are subsets. Consider example 1, which shows the first ten measures of Wheeler's tune "Quiso," released in 1976.5 Because improvisation plays an important role in jazz performance, understanding how a given chord functions within a tune is paramount to producing a convincing solo.

\section{QUIS0}

KENNY WHEELER
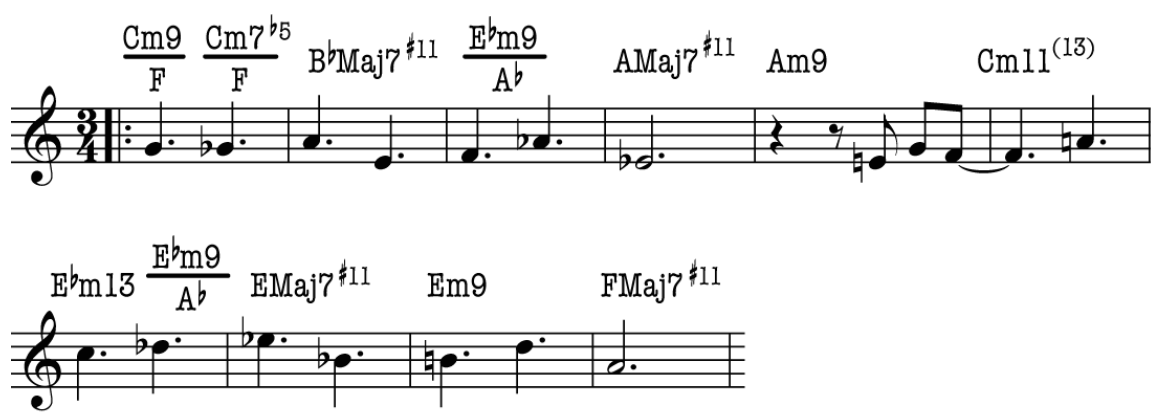

Example 1. Lead sheet for Kenny Wheeler's "Quiso," mm. 1-10

In the example, despite the fact that the chord succession is non-functional, identifying an appropriate scale to use while improvising over the changes

4 Wheeler is not mentioned is any of the following jazz history surveys: Gridley 2009; Tanner, Megill, and Gerow 2009; Martin and Waters 2012.

5 The lead sheets included in this article are transcribed from handwritten copies made by Wheeler and are reproduced with his permission. 
in these measures is relatively straightforward, since there is a one-to-one relationship between a chordal extension and a mode (for instance, min13 = Dorian). Other chords in the excerpt, however, are a little more ambiguous: Cming/F and $E^{b} m i n g / A^{b}$ suggest either Dorian or Aeolian. However, because both of these chords essentially return at later points in the succession with an added thirteenth $\left(\mathrm{Cmin11}^{\left({ }^{13}\right)}\right.$ in $\mathrm{m} .6$ and $\mathrm{E}^{\mathrm{b}} \mathrm{min} 13$ in $\left.\mathrm{m} .7\right)$, it is possible to understand each to be a subset of its respective Dorian mode. Also, Maj; $\# 11$ suggests the Lydian mode, and we can see that Wheeler uses this chord type in four of the ten measures. When following a chord-scale approach, therefore, a loose consistency might be observed across the entirety of the excerpt since, with the exception of the chord in the second half of $\mathrm{m}$. 1, it would appear that mm. 1-10 use only Dorian and Lydian modes, often alternating between successive measures.

The problem with taking a strictly chord-scale approach, especially in such a repertoire as Wheeler's music, is that it fails to reflect the linearity that might exist in a tune's melody. For instance, the lower portion of example 2 shows the structural melody of mm. 1-4 in "Quiso." Here, the melody's starting pitch, $\mathrm{G}_{4}$, connects to the durationally accented $\mathrm{E}^{b} 4$ three bars later, in $\mathrm{m}$. 4, via a stepwise descent, from $\hat{3} \rightarrow \hat{1}$ in $E^{b}$ Lydian; the descent is represented in the example by the notes with open noteheads, signifying their primary role in the structural melody. The example shows that $\hat{3}$ connects to $\hat{2}$ through a chromatic passing tone $\left(G^{b} 4\right)$, with $\hat{2}$ beginning in the second measure. ${ }^{6}$ Following this, E4 functions as a chromatic lower neighbour to $\hat{2}$. The example represents both the chromatically altered $\mathrm{G}^{\mathrm{b}} 4$ and $\mathrm{E}^{\mathrm{b}} 4$ with smaller noteheads, signifying their subsidiary role in the structural melody. Hearing $\mathrm{G}^{b} 4$ as a passing tone discounts any real harmonic change occurring in the second half of m. 1 $\left(\mathrm{Cmin} 7^{\mathrm{bs}} / \mathrm{F}\right)$; instead, it is a single chord throughout the entire bar $(\mathrm{Cming} / \mathrm{F})$ that has a momentarily altered pitch. This is similarly the case in $\mathrm{m}$. 2, where the sharp eleventh included in the chord (E) is actually the result of a linear melodic event, pointing towards a more structural pitch, $\mathrm{F}_{4}$, in $\mathrm{m}$. 3. Accordingly, the chord in the second half of m. 1, as well as the harmony in m. 2, is a subset of $\mathrm{E}^{b}$ Lydian, but contains momentarily altered notes.

Returning to the melody, the notated pitches of mm. 2-3 are chordal skips between members of the underlying chords. These skips are represented in the lower portion of the example by the slurs between corresponding notes. By verticalizing these skips, the melody's $A^{b} 4$ is understood as a chromatic lower neighbour to A ( $\hat{4}$ in $\mathrm{E}^{b}$ Lydian). Accordingly, example 2 represents $\mathrm{A}^{\mathrm{b}} 4$ with a smaller notehead in the lower portion, and shows an implied $A^{b} 4$ connected to the more structural $\mathrm{E}^{b}$; the actual resolution from $\mathrm{A}^{b}$ back to $\mathrm{A}$ can be understood to occur in the bass line.7 These observations help to support the $\hat{3} \rightarrow \hat{1}$ linear descent across the tune's first four measures. Yet such connections may

6 In the example, $\hat{2}\left(\mathrm{~F}_{4}\right)$ is placed in parentheses in the structural melody in order to represent its initially implied status, over Bbaj7.

7 It is precisely because of the bass note in m. 4, upon which the tune's first phrase concludes, as well as the melodic motion just mentioned that I am preferring $\mathrm{A}^{\natural}$ over $\mathrm{A}^{b}$. Analyzing the melody in this way helps to support my preference for $\mathrm{E}^{b}$ Lydian as the most prevalent set throughout $\mathrm{mm}$. 1-4. 
not necessarily be evident when following a chord-scale approach that would likely change scales every other bar.

Like example 2, Wheeler's melodies are often connected across the barline; as such, they often negate a one-measure-at-a-time interpretation, one frequently advanced by conventional chord-scale theory. ${ }^{8}$ In an attempt to address this issue, the following article will show how, despite Wheeler's relatively chromatic-and, at times, non-diatonic-chord successions, his melodies engage longer-reaching relationships that prioritize certain pitch-class collections over others. This hierarchical method of interpreting pitch-class (pc) content in Wheeler's melodic writing helps to promote particular continuities in his compositions, providing insight into those non-functional chord successions. This, in turn, helps to make Wheeler's music more manageable for both analysts and performers. The prime goal of the article will be to show how continuity across less conventional chord successions in some of Wheeler's music is plausible when taking a top-down analytical approach-that is, when prioritizing the melody.

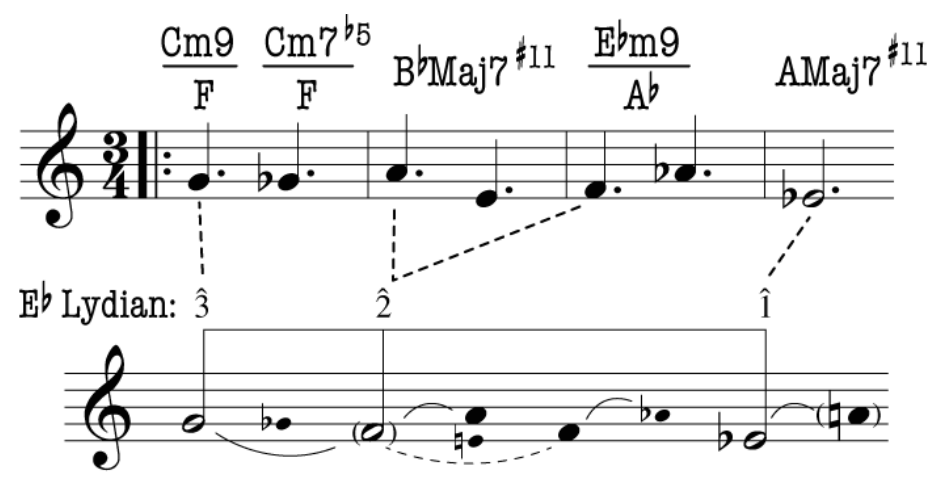

Example 2. Structural melody of phrase 1 (mm. 1-4)

Throughout the remainder of this article, I will describe the pitch-class collection that is prioritized within a given passage as the referential (pitch-class) set, or RS. In primarily diatonic tonal music, the major or minor scale that corresponds to the key of the composition could be described as referential, in the sense that listening may be oriented by its continuous presence in both the melody and harmony. Generally, the collection is signalled by the prominence and repetition of its most important scale degrees. Details of tension and resolution, melodic structure, harmonic syntax, and form may all be clarified by their relationship with the underlying scale. In more chromatic repertoires, rapid circulation of pitch class may make these details more challenging to comprehend. Faced with such music, the listener who seeks orientation may

8 Of course, linear connections that extend beyond a single measure are not unique to Wheeler. They are, however, characteristic of both his compositional and his improvisational style. The issue here is that chord-scale theory tends to discuss individual chords and their generating scales in a oneto-one manner-an especially vertical and relatively non-linear approach. 
still naturally gravitate towards emphasized or repeated tones, in the melody or harmony or both. The opportunity to hear pitch-class persistence as a form of continuity in Wheeler's less conventional chord successions is a strong motivation behind the present article.

In the discussion that follows, I will also adopt the term referential tonic, or $\mathrm{RT}$, to describe the pc that features most prominently within the RS, whether or not this pc functions melodically as a traditional tonic would. Please note the pc-sets that are considered to be most referential are partially ordered, beginning with the RT. Beyond the RT, however, the remaining members can remain unordered. 9

It is possible, and in fact likely, that a given passage will contain pcs other than those designated as belonging to the RS. Whenever possible, however, I consider these non-RS members not as members of new sets, but instead as momentary alterations of RS members. Such an interpretation obtains if the members of the RS are chosen so that non-members of the RS relate to them by semitone. This was demonstrated above, in "Quiso," where the chords in the second half of $\mathrm{m} .1$ and in $\mathrm{m}$. 2 were not interpreted as subsets of, for instance, C Locrian and $\mathrm{B}^{\mathrm{b}}$ Lydian, respectively, but instead as both belonging to the more prevalent $\mathrm{E}^{b}$ Lydian collection, albeit with momentarily altered notes. Conceptualizing the music in this manner allows one to describe every pitch in a given passage as either a member of the RS or as an alteration of a member, and thus minimizes any deviation from the most referential set. ${ }^{10}$

The idea of temporarily altering members of a referential set in order to obtain new pcs resonates with earlier jazz theoretical models. For instance, Russell (1959) introduces his Lydian chromatic scale as a combination of the seven "parent scale" members interspersed with five "altered" members, as shown in example $3 .{ }^{11}$ Here, members are labelled using roman numerals I-VII, with + or - signifying alterations of these members by plus or minus one semitone. Thus, Russell's chromatic concept retains the presence of a diatonic collection, but fills it in with chromatically altered members.

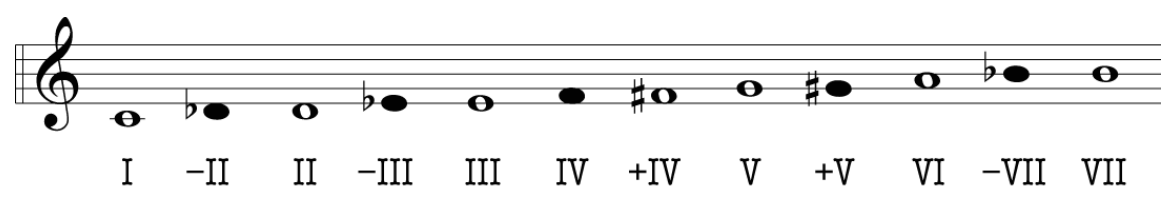

Example 3. Russell's representation of a Lydian chromatic scale

9 Throughout this article, I will use angle brackets to represent ordered pc sets and parentheses to represent unordered $\mathrm{pc}$ sets.

10 Dmitry Tymoczko (jokingly) terms this the "fundamental theorem of Jazz" and states that, because improvisers of jazz often make use of scales that do not contain steps larger than two semitones, they can never be more than one semitone away from a member of their chosen scale. As a result, any "wrong" note can be analyzed as a chromatic neighbour to an adjacent member of the scale. See Tymoczko 2011, 156-57.

${ }_{11}$ Russell's system of labelling could be compared to set theory, which uses integer notation for pcs (o-11), eliminating any sense of hierarchy. 
Despite being presented in unfamiliar successions, traditional chord types abound in Wheeler's compositions. These include $\mathrm{MM} 7, \mathrm{~mm} 7$, and (more rarely) $\mathrm{Mm}$, all with and without extensions, alterations, and omissions. Generally speaking, the continued use of these chords reflects the ongoing significance of improvisation in jazz, as well as the influence of chord-scale theory. These tertian chords not only play a role within the pre-composed portions of a tune but, since each chord tends to have an associated scale, they also serve as vehicles for improvisation. Thus, the root of a given chord serves as the basis on which an improviser will build a corresponding scale.

The scales associated with the traditional chord types listed above are primarily diatonic, and it is often only after introducing chromatic extensions and alterations that chord-scale theory makes use of non-diatonic collections such as whole tone and octatonic scales. Of course, theorists have shown how other types of non-diatonic collections have made appearances in jazz tunes, particularly those of the post-bop era. For instance, Keith Waters and Kent Williams (2010) refer to hexatonic collections in Wayne Shorter's harmonic writing, arrived at through chords that use set class (0148) as a subset. Also, Matthew Santa's (2003) and Masaya Yamaguchi's (2002) studies of John Coltrane invoke sets of limited transposition, such as the nonatonic collection. Despite such observations, however, non-diatonic collections such as these are rare. Therefore, in consideration of the salience of tertian chord structures and their associated diatonic collections, diatonic collections will be the preferred RS throughout this article.

Let us now consider example 4, which shows a lead sheet for the first sixteen measures of the Wheeler tune "Who Are You?," which appears on the album Azimuth '85. The entire tune consists of thirty-two measures; it is in AABA song form, in which each section spans eight measures. The tune's melody is based entirely on a single white key diatonic collection. Despite being harmonized by chords that, at times, contradict this collection, the persistence of a single scale in the melody encourages hearing it as referential.

The recording features vocalist Norma Winstone singing the first sixteen measures unaccompanied, thus allowing the listener to become acquainted with the diatonic collection prior to any harmonic elaboration and embellishment. ${ }^{12}$ Durational accents in the melody in mm. 1-16 help to prioritize particular pitches. For instance, the durational accent on $\mathrm{E}_{4}$ in $\mathrm{m}$. 2, the fifth of the opening $A_{3}$, signals this note's significance. Also, because the notes $<\mathrm{G}_{4}$, $\mathrm{E}_{4}, \mathrm{~B}_{3}>$ at the end of $\mathrm{m} .4$ function as a pickup to the proceeding measure, $\mathrm{A}_{4}$ is understood to be sustained across the entirety of the measure. Thus, the melody in mm. 1-4 places particular significance on the note A, as well as its fifth, $\mathrm{E}$, suggesting the possibility of $\mathrm{A}$ as referential tonic. Also, the repetition of the four-note pc series $<A, G, E, C>$ in mm. 1-8, which outline an Amin7 chord, provides further support for RT A.

12 Pitch class $\mathrm{F}$ is not stated in the first sixteen measures of the melody. It is not until the downbeat of $\mathrm{m} .21$ (not shown), with the entrance of $\mathrm{F}_{4}$, that the diatonic collection is therefore completed. 


\section{WHO ARE YOU?}
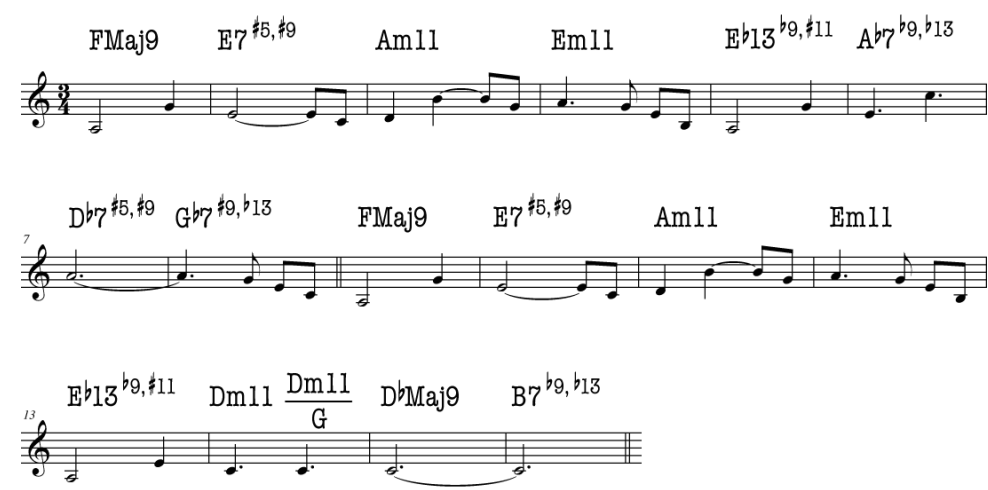

Example 4. Lead sheet for Kenny Wheeler's “Who Are You?," mm. 1-16 (Azimuth '85 1985)

Let us now turn our attention to the chords. Example 5 shows a possible realization of the chord-series in mm. 1-4; for a more clear representation, the melody has been transposed up one octave. The roman numerals included in the example show my preference for A as RT. Though the lead sheet chord in m. 2 contains alterations, the example shows how $\mathrm{E}^{\# 5, \# 9}$ only contains one pitch that is not a part of the white-key collection used in the melody, G\# (signified by a small notehead size). ${ }^{13}$ Except for this pitch, the other alterations in $\mathrm{m}$. 2 's chord support an overarching RS, which, when considering the melody and harmony together, suggests A Aeolian.

The following measures present chords that are not overtly related to this RS; they may be rationalized, however, by considering two characteristic

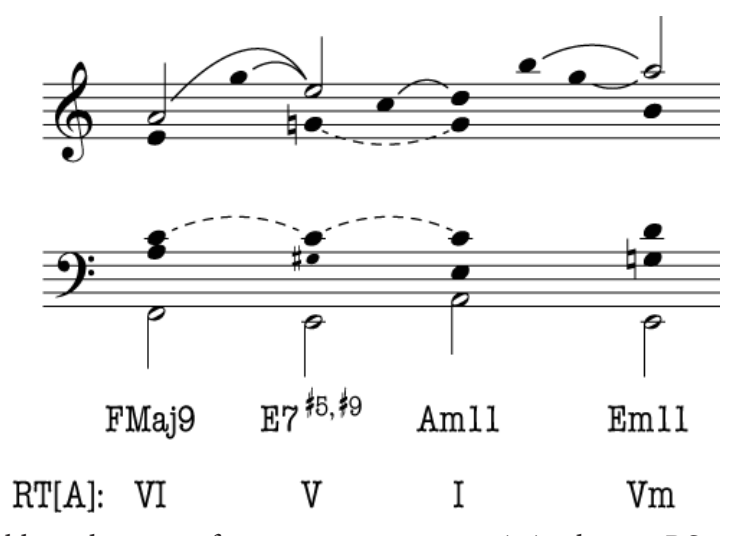

Example 5. Possible realization of mm. 1-4, supporting A Aeolian as RS

$13 E_{7} \sharp 5, \sharp 9=<E, G \sharp, B \#, D, F \#>=<E, G \sharp, C, D, G^{\natural}>$. Of course, in the key of A minor, $G^{\sharp}$ is the common leading tone. The argument here is that $\mathrm{G}$ conflicts with the collection presented in the melody, strictly speaking. Collectional persistence between the melody and the underlying harmonies is, therefore, supported by the alterations in $\mathrm{m}$. 2's chord, where $\#_{9}=\mathrm{G}^{\natural}$. 
procedures of jazz writing: harmonic sequence by descending fifth, and tritone substitution. Hearing the chords in mm.5-8 as tritone substitutions for secondary dominants of white-key triads, it is possible to comprehend the members of these substitute chords as altered members of the tonicized RS chords. The first two of these are shown in example 6, with non-RS members represented in grey. Here, the roots of the tritone-substitutes ( $\mathrm{E}^{b}$ and $\mathrm{A}^{b}$, respectively), as well as their respective sevenths $\left(\mathrm{D}^{b}\right.$ and $\mathrm{G}^{b}$, respectively), are analyzed as semitone displacements of the RS members to which they would traditionally resolve. ${ }^{14}$ This is, similarly, the case with the fifths of the tritone-substitutes. ${ }^{15}$

The harmonic alterations specified on the lead-sheet chords in mm. 5-8 also support the sense of a single, persistent RS, and focus on RT A. Example 7 shows the pc content of the Mm7 cycle heard in these measures. Though the alterations vary from chord to chord, the resulting pcs are the same: A and E. These pcs are highlighted in the example by the broken lines that connect them from chord to chord. The only exception is in $\mathrm{m}$. 8, where $\mathrm{E}\left(\mathrm{or} \mathrm{F}^{\mathrm{b}}\right.$ ) is an unaltered chord tone; also, the $\#_{9}$ over $\mathrm{G}^{b}=\mathrm{A}$, and ${ }^{b}{ }_{13}$ over $\mathrm{G}^{b}=\mathrm{D}$ ( which are members of A Aeolian). The inclusion of these notes across a relatively chromatic passage keeps the opening RS alive and provides a significant sense of continuity.

The recording of "Who Are You?" on the aforementioned album features a trumpet solo by Wheeler, a transcribed excerpt of which is given in example 8 . Note that, just prior to the start of the solo, pianist John Taylor modulates to a new tonal centre, resulting in a tritone-transposition of the entire form. In following the current analysis, I will consider Wheeler's solo in $\mathrm{E}^{b}$ Aeolian. ${ }^{16}$

\section{$\mathrm{E} b 13^{b 9, \$ 11}$
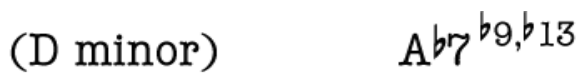 \\ (G major)}
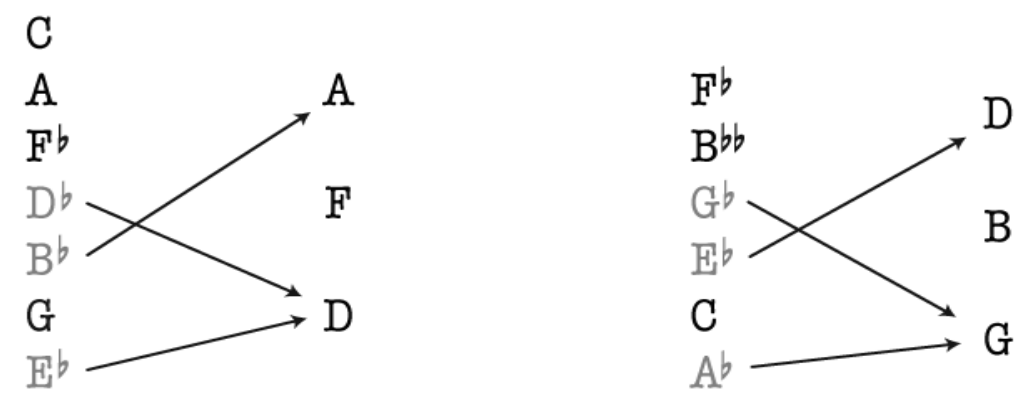

Example 6. Members of tritone substitutes as alterations of RS members

14 The sevenths are the enharmonically respelled leading tones of the following chords.

15 In a case where the actual $\mathrm{Mm} 7$ chords were not replaced by their tritone subs, $\mathrm{B}^{b}$ and $\mathrm{G}^{b}$ are altered ninths, which resolve to the fifth of D minor and $\mathrm{G}$ major, respectively. Other resolutions would also occur between these chords, such as the third of each tritone substitute progressing to the third of the RS chords. However, because these are all members of the governing RS, their presence need not be addressed in these particular cases.

16 The tritone relationship between the vocal and instrumental sections is highlighted more locally throughout the tune by the many tritone-substituted chords, as discussed above. 


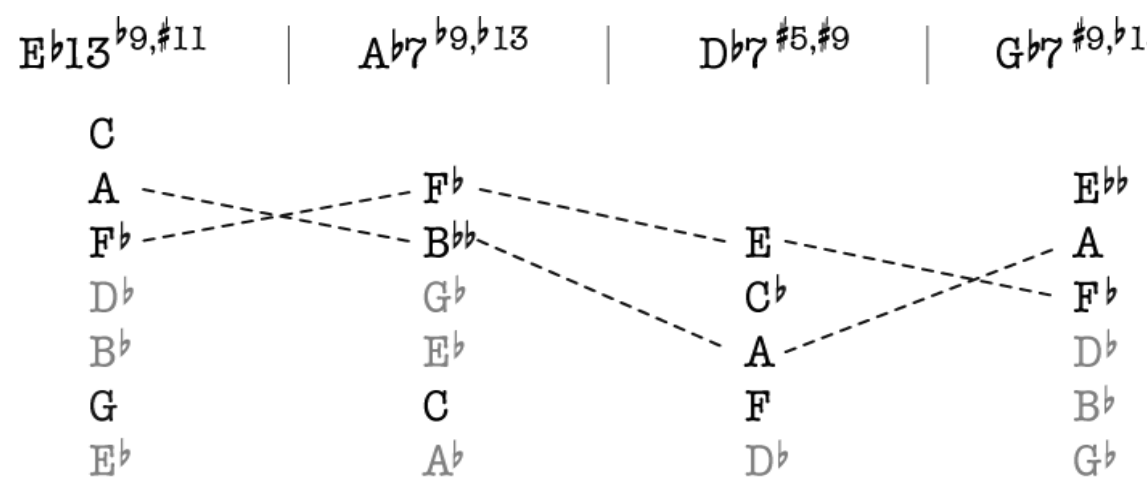

Example 7. Pitch-class content of chord series used in mm. 5-8

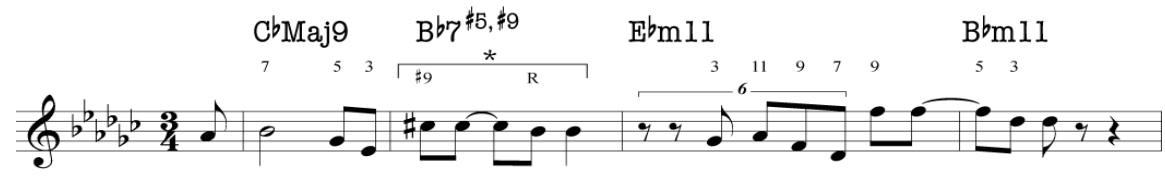

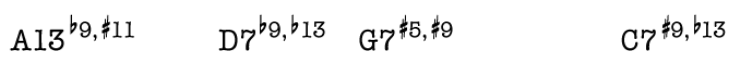
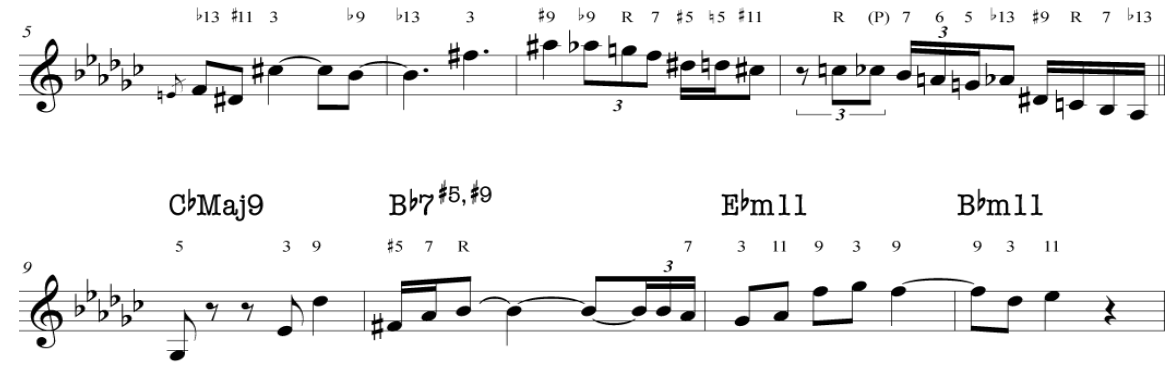

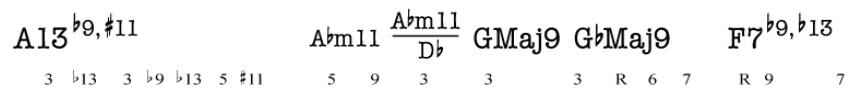

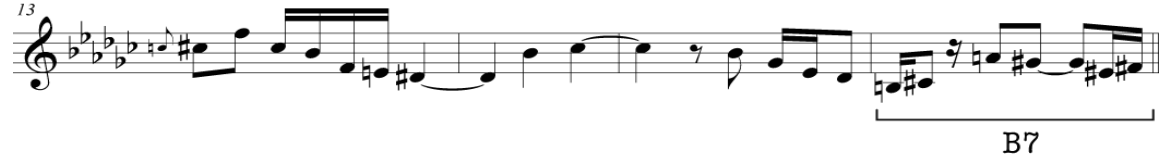

Example 8. Wheeler's solo with chord-tone analysis, "Who Are You?" (mm. 1-16, 1:151:47), rhythm approximate 
The example shows Wheeler's solo over mm. 1-16, with pitches notated and labelled above the staves in relation to the underlying chords. ${ }^{17}$ Please note that, in $\mathrm{m}$. 16, Wheeler includes both altered extensions in his solo. But in view of the overall choice of notes in this measure, it seems more appropriate to analyze Wheeler's solo here as based on $\mathrm{B} 7$, the tritone substitution of the notated F7. Therefore, the chord tones have been labelled according to B7, and not the notated F7.

Example 9 re-notates Wheeler's solo exclusively in $\mathrm{E}^{b}$ Aeolian, which is the tritone transposition of the RS posited during the head. There are significantly fewer accidentals than in example 8 , revealing that, regardless of the underlying chords, the majority of Wheeler's solo is consistent with a single, overarching RS. In this regard, the $C_{\sharp} \rightarrow B^{b}$, augmented-second leap that is identified in the second measure of example 8 (the $\# 9$ and root of the underlying chord) is enharmonically reinterpreted as a minor third leap from $\hat{7} \rightarrow \hat{5}$ in $\mathrm{E}^{b}$ Aeolian, and highlighted by the brackets and asterisks. With the exception of the grace note in $\mathrm{m}$. 5, every note between $\mathrm{mm}$. 1-6 can be understood as a member of $\mathrm{E}^{b}$ Aeolian (the grace note, $\mathrm{E}_{4} 4$, is a displaced chromatic passing tone between $\mathrm{D}_{5} b_{5}$ and $\mathrm{F}_{4}$ ). In $\mathrm{m}$. 7, Wheeler momentarily deviates from the most prevalent RS by raising 3 in order to accommodate the chordal root in that measure $\left(\mathrm{G}^{\mathfrak{b}}\right)$ - and similarly in $\mathrm{m} .8$, where $\mathrm{C}^{b}\left(\hat{6}\right.$ in $\left.\mathrm{E}^{b}\right)$ is temporarily altered and raised to $C 4^{\natural}$. Thereafter, $\mathrm{D}_{5} 5$ is analyzed as a chromatic passing tone that connects $\hat{i}$ to $\hat{\bar{t}}$, which is then similarly connected to $\hat{6}$ across the measure,

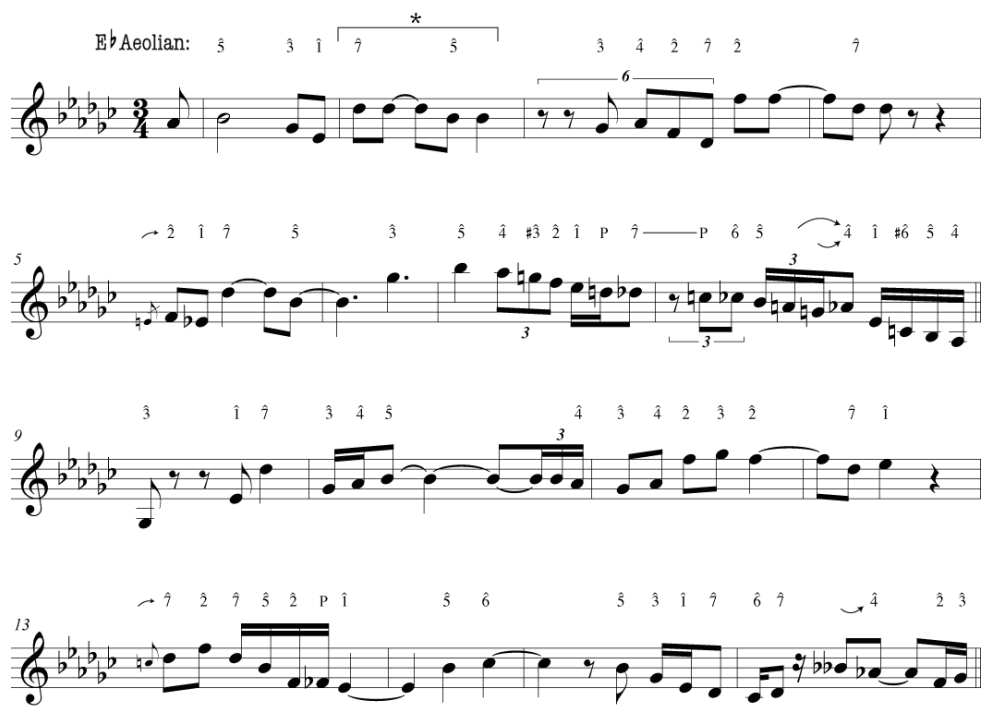

Example 9: Wheeler's solo with RS Eb Aeolian analysis, "Who Are You?" (mm. 1-16, 1:151:47), rhythm approximate

17 The recording includes the chord $\mathrm{G}^{b}$ Maj9 in $\mathrm{m}$. 15, which is not included on the lead sheet. 
identified by the horizontal line in the example. In m. $8, \hat{6}$ is approached by a chromatically altered double-neighbour figure, represented by the curved lines with arrowheads. Measures 9-15, with the exception of the grace note and a chromatic passing tone in $\mathrm{m} .13$, are all members of $\mathrm{E}^{b}$ Aeolian. In the final measure, $B^{b b} 4$ is an appoggiatura that resolves to a member of the referential set, $A^{b}$. By presenting Wheeler's solo in this way, we can see that, like in the original melody, Wheeler accommodates many of the tune's chromatic harmonies with a single set. As a result, it is possible to analyze many of the pcs that are not members of the set as chromatically altered RS members, minimizing our sense of deviation.

Example 10 shows the lead sheet for the Wheeler tune "Kind Folk," which first appeared on the album Music for Large and Small Ensembles, released in 1990, as part of the Sweet Time Suite. ${ }^{18}$ The tune was later rearranged and included on the album Angel Song, released in 1996. ${ }^{19}$ This latter version serves as the principal source for the following analysis, but performances of "Kind Folk" are also featured on the albums Still Waters (1999), and Lee Konitz and Kenny Wheeler Quartet: Live at Birdland Neuberg (2000), the former being a duo recording with pianist Brian Dickinson. ${ }^{20}$

Two out of the three post-1990 recordings mentioned above begin with a solo bass vamp not notated on the original lead sheet, a transcription of which is shown in example $11{ }^{21}$ The vamp consists of arpeggiated perfect fifths separated by a major third: $\left\langle\mathrm{G}_{2}, \mathrm{D}_{3}\right\rangle \rightarrow\left\langle\mathrm{B}_{2}, \mathrm{~F}_{3}\right\rangle$. There are various ways to interpret this vamp. For instance, one might understand an initial G-rooted chord moving to a second chord that has B as its root. This interpretation leaves the quality of the chords unknown, since neither arpeggiation includes the chordal third. Alternatively, by grouping the dyads together into one chord-for instance, GMaj7-one could understand a single scale to govern the entire vamp, such as $\mathrm{G}$ Ionian or G Lydian. This interpretation would likely prioritize G, suggesting it as RT.

A third interpretation of the opening vamp would consider each dyad as belonging to different diatonic scales, opening up the possibility of chord successions such as GMaj $\rightarrow$ BMaj or Gmin $\rightarrow$ Bmin. Exact transposition of chords, heard in successions such as these, would not be uncommon in contemporary jazz (or pop). ${ }^{22}$ In the case of "Kind Folk," however, with the limited information provided up to this point in the tune, my preference is to analyze the fifths

18 Wheeler, "Kind Folk," 1990. Note that "Kind Folk" is included on the album as part of "Part 2-For H. / Part 3-For Jan" (track 2), and is performed in common time.

19 Wheeler, "Kind Folk," 1996. Described as "an album of celestial beauty that marks a latecareer high point for Wheeler" (Brambarger 1997, 1), Angel Song features Wheeler on trumpet and flugelhorn, Lee Konitz on alto sax, Bill Frisell on guitar, and Dave Holland on bass.

20 Dickinson and Wheeler, "Kind Folk," 1999; Konitz and Wheeler, "Kind Folk," 2000.

21 The Still Waters recording also includes a similar vamp, played on the piano, but with the chords filled in.

22 Miles Davis's "So What" is such an example, which is based on the chord succession Dmin7 $\rightarrow$ Ebmin (M. Davis, on Kind of Blue, Columbia CS 8163, 1959). The same succession of chords is used in John Coltrane's "Impressions" (J. Coltrane, on Impressions, Impulse AS-42, 1963). These types of chord-transformations can also be found in classical music, and are described in Kopp 2002. 


\section{KIND FOLK}

A
GMajr ${ }^{\$ 11}$
$B \min ^{\text {(add 9) }}$

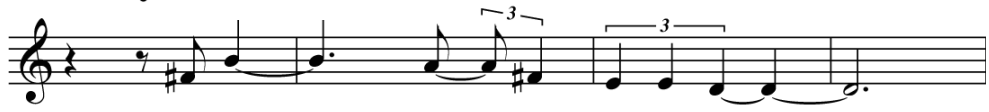

GMajr $7^{\$ 11}$

$\mathrm{Bmin}^{\text {(add 9) }}$

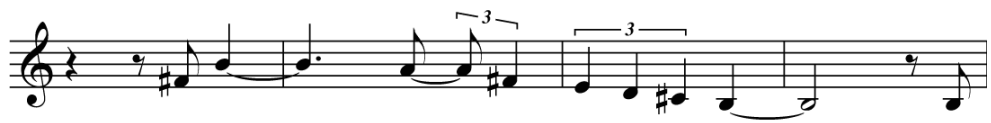

FMaj7 $7^{\# 11} \quad \mathrm{~F} \$ \mathrm{~m}^{7^{65}} \quad \mathrm{CMaj} 7 / \mathrm{G} \quad \mathrm{G} \$ 7^{\$ 5, \$ 9}$
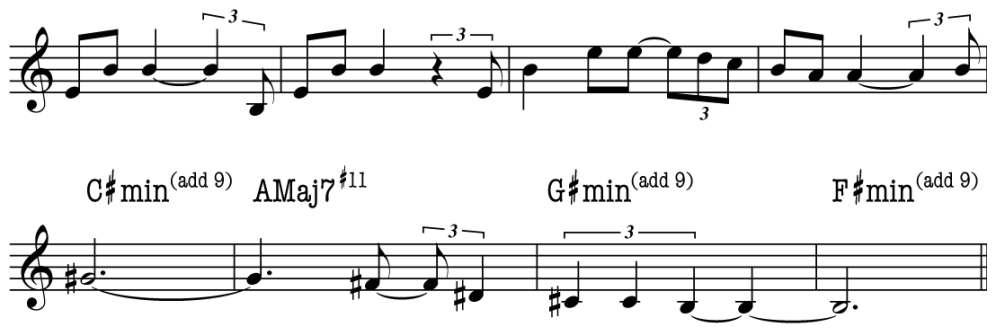

B

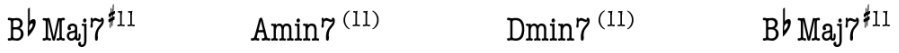
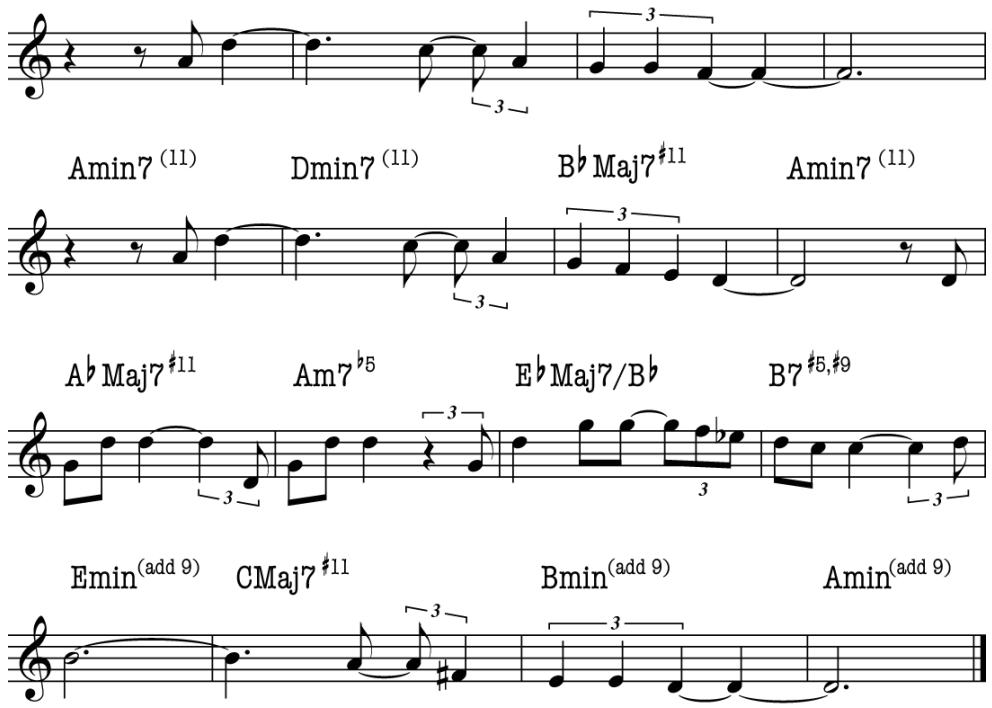

Example 10: Lead sheet for Kenny Wheeler's "Kind Folk" 


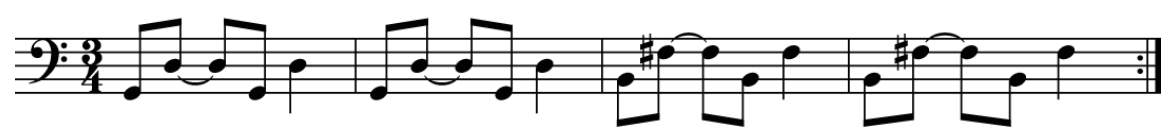

Example 11: Opening bass vamp for "Kind Folk"

as members of a single scale. Further, the equal distribution of $\mathrm{G}$ and $\mathrm{B}$ across the measures (both in duration and harmonic rhythm) suggests a chord-root $\mathrm{G}$ progressing to a chord-root B. Collectively, therefore, the vamp implies the chord succession GMaj $\rightarrow$ Bmin, or some variation, with both chords generated by the same RS. This initial interpretation proposes the governing set as G Ionian, as opposed to, for instance, B Aeolian or B Phrygian. ${ }^{23}$

Excluding the vamp, "Kind Folk" is thirty-two measures long, with an A $+\mathrm{B}$ internal division of sixteen-plus-sixteen measures. ${ }^{24}$ Various musical details within each section, such as changes of focal pitch, changes in harmonic rhythm, and, as we shall see, changes of RS, result in shorter subdivisions. As well, the chord types are rather diverse throughout and rarely manifest any conventional relationships. As we shall see, however, one set features prominently, and the particular arrangement of the referential sets asserts that the tune is governed by a single RT.

To determine the RS, let us first consider how priority is established within the entire collection of pcs generating the melody in the opening eight measures $(B, C \#, D, E, F \#, A)$. In mm. 1-4, a reduction of which is shown in example 12 , priority is initially given to $\mathrm{B}$ as a result of the $\hat{5} \rightarrow \hat{1}, \mathrm{~F}_{4} \rightarrow \mathrm{B}_{4}$ leap. ${ }^{25}$ The return of $\mathrm{F}_{4} 4$, followed by a descent to $\mathrm{D}_{4}$ supports hearing a $\mathrm{B}$ minor triad arpeggiated across $\mathrm{mm} .1-4$; this is represented in the example using slurs. Because $\mathrm{C} \#$ does not occur in the melody until m. 7, one might hear mm. 1-4 as a "stepwise" descent through a B minor-pentatonic collection. The upper portion of the example, therefore, includes scale degrees that refer to members of this scale. Following from these observations, B is understood as the most structural melodic pitch; its priority is represented by the open notehead.

Example 13 presents a reduction of the next four measures (mm. 5-8). Here, the descent to $\mathrm{B}_{3}$ initiated in the tune's first four measures is completed. The broken line in the example shows that the structural $\mathrm{B}$ is essentially prolonged across $\mathrm{mm}$. $5-8$, from $\mathrm{B}_{4} \rightarrow \mathrm{B}_{3}$. Accordingly, $\mathrm{B}$ is understood as the RT in $\mathrm{mm}$. $1-8$, and the melody is understood as an incomplete diatonic scale, as opposed

23 Recall that I am preferring diatonic collections.

24 I will not include the opening vamp as part of the total number of measures, or when referencing measure numbers; thus, m. 1 will refer to the first measure on the original lead sheet, at the entrance of the melody.

25 This interpretation would contradict prioritizing G, as suggested in the discussion of the opening vamp. Were G understood as RT, then the melody's opening leap might be analyzed as the third and seventh, or guide tones of G. Following the approach presented in this article, however, I begin by considering the unaccompanied melody. Presented in this way, therefore, my inclination is to hear the opening leap as $\hat{5} \rightarrow \hat{1}$ in $\mathrm{B}$, as suggested. 


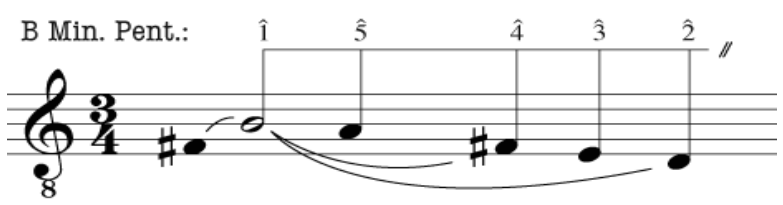

Example 12: Structural melody of mm. 1-4

to an "expanded" pentatonic one. ${ }^{26}$ Of course, when considering the melody in isolation, the exact scale is not clear, since $\hat{\sigma}$ is absent. However, the scale is completed by the underlying chord series, which includes $\mathrm{G}^{\text {h }}$, asserting B Aeolian as the governing RS.

Support for B as RT is also found in various improvisations on the tune, some of which are shown in examples 14a-c. Examples 14a and 14b show improvisations by Bill Frisell and Lee Konitz: note how both musicians include $\hat{6}$, supporting B Aeolian, but exclude $\hat{2}^{27}$ Example $14 \mathrm{C}$ is taken from Wheeler's solo, which, just as in the tune's pre-composed melody, includes all members of B Aeolian except $\hat{6}$. Thus, all three soloists utilize the B minor-pentatonic collection as a common subset in their improvisations, but interject one of the two remaining members of the governing RS. Examples $14 \mathrm{a}-\mathrm{b}$ also show how both Frisell and Konitz reinforce B as RT by emphasizing members of the tonic triad throughout their improvisations. Similarly, Example 14c shows that Wheeler essentially descends stepwise through almost the entire set, starting on $\mathrm{D}_{5}(\hat{3})$ and ending on $\mathrm{B}_{3}(\hat{\mathrm{i}})$.

When placed in association with the melody in mm. 1-8, the chord used in $\mathrm{mm} .3^{-4}, \mathrm{Bmin}^{(\mathrm{add} 9)}$, now sounds like tonic. As a result, the tune's opening chord, GMaj $\sharp^{11}$, is analyzed as a large-scale appoggiatura to Bmin ${ }^{(\text {add9) }}$, an ornamental chord that encompasses the ultimately more focal Bmin ${ }^{(\text {add9) }}$. Because almost all of the notes in GMaj $7^{\sharp 11}$ are common with $\mathrm{Bmin}^{(\text {add9) }}{ }^{\text {, linearity }}$ between the two events is expressed by the only unique pitch between the two chords, $\mathrm{G}^{\text {巾. }}$. Given the present context, it could be possible to hear the relationship between $G^{\natural}$ (in GMajz $\#^{11}$ ) and $F \#$ (in Bmin ${ }^{(\text {add9) }}$ ) as a $b \hat{6} \rightarrow \hat{5}$-motion that is common in minor-mode compositions. ${ }^{28}$ The upper staff in example 15 shows one way that an accompanist might perform the progression, maintaining the aforementioned melodic motion, where $\mathrm{G}_{4}$ moves down by semitone to $\mathrm{F}_{4} 4{ }^{29}$ This interpretation not only supports the idea of a static progression in mm. 1-8

26 Such expansion can be found in other contemporary jazz, such as that by pianist McCoy Tyner. Paul Rinzler notes how 2 was the most common expansion to the minor pentatonic scale in Tyner's vocabulary: $\left\langle 1,2, b_{3}, 4,5,{ }^{b} 7\right\rangle$. The addition of this note enabled a greater number of quartal chords, such as $\langle 2,5,1\rangle$ and $<2,5,1,4\rangle$. See Rinzler 1999, 51.

27 Bill Frisell and Lee Konitz, "Kind Folk," composed by Kenny Wheeler, produced by Manfred

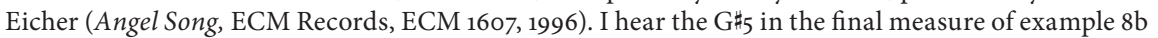
as a chromatically altered pitch that is functioning as an incomplete neighbour to the following $\mathrm{A}_{5}$, and not as a member of B Dorian. The motive, here, is an anacrusis to m. 9 .

28 In following the notated lead-sheet chords, where the bass supports G moving to B, this relationship occurs in pc space, or in an upper voice (as shown in example 15).

29 The example excludes the major 7 th $(F \sharp)$ from the first chord in favour of a bijective voice leading. Because it is a common jazz practice to vary harmonic voicings when comping, the voicing 


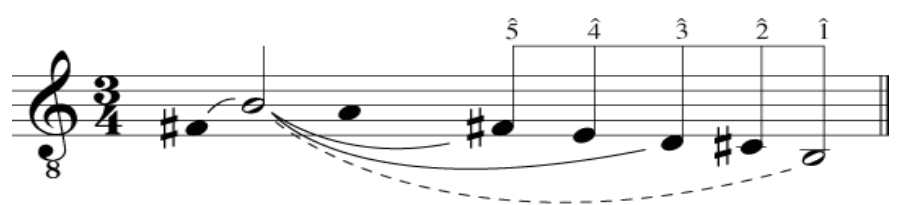

Example 13: Structural melody of mm. 5-8

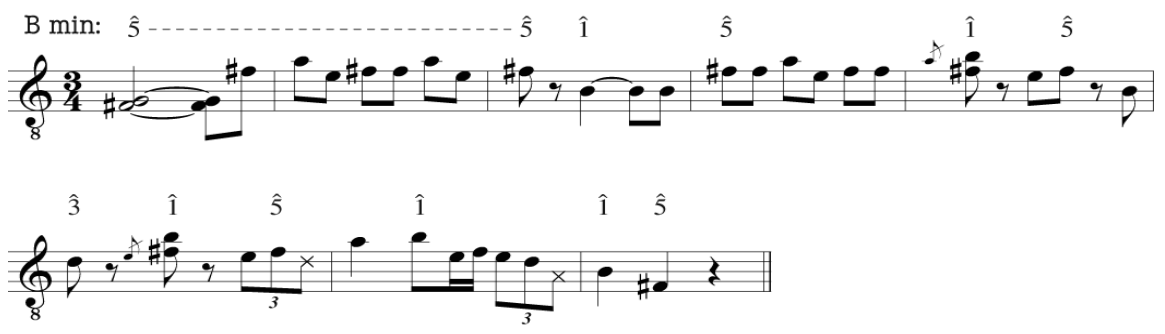

Example 14a: Bill Frisell, solo on "Kind Folk" (mm. 1-8, 1:08-1:21)

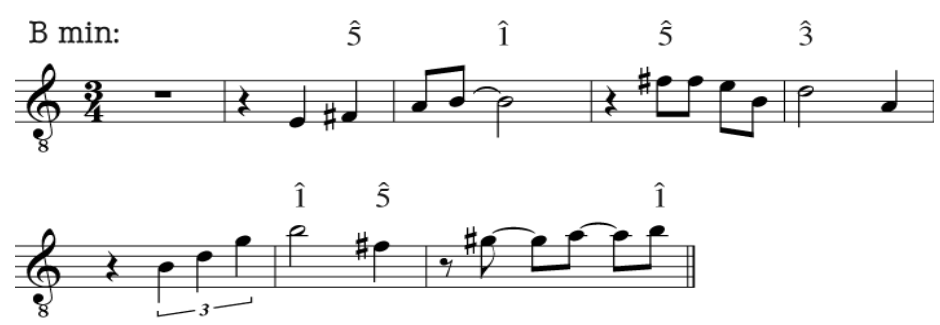

Example 14b: Lee Konitz, solo on "Kind Folk" (mm. 1-8, 4:28-4:40)

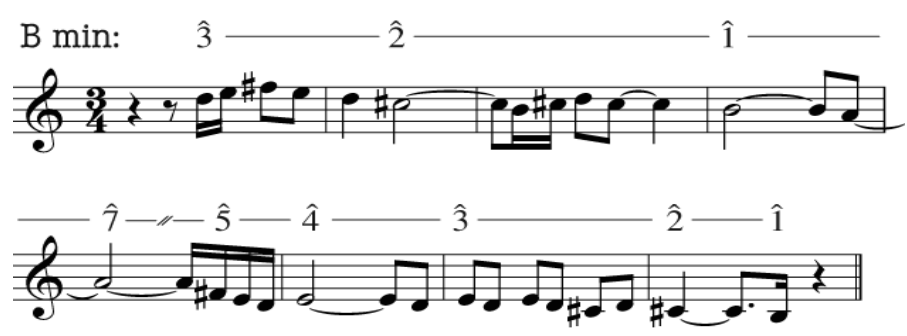

Example 14c: Kenny Wheeler, solo on "Kind Folk" (mm. 1-8, 2:49-3:01)

in regards to harmonic function, but it completely eliminates the sense of any real harmonic change..$^{30}$

Common modal-jazz performance practice permits an accompanist to realize a given chord succession in various ways. For instance, example 16 presents

given in the example is certainly possible. The bass line included in the example represents approximately what is included on the recording.

30 When following a more traditional chord-scale approach, the chord changes might suggest G Lydian followed by B Aeolian (or perhaps B Dorian). Though these two collections are rotations of the same pcs, changing modes on each chord might result in a continuously changing tonic in an improviser's mind, as well as a change of fingering and/or position on the instrument. 


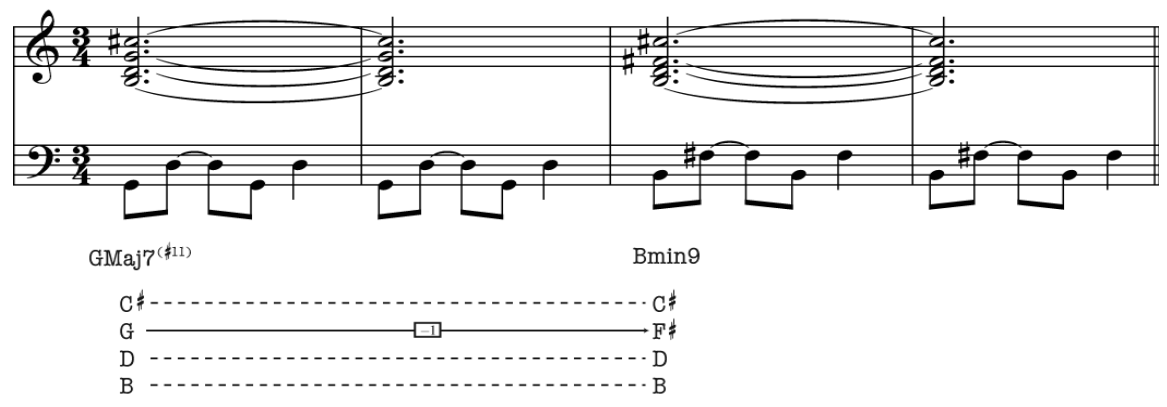

Example 15: Voice leading between GMaj7\#11 and Bming (mm. 1-4)

a transcribed excerpt from Bill Frisell's performance of the opening of the tune. Note how Frisell includes both the pitches F $\#$ and G on Bmin ${ }^{\text {(add9) }}$ (highlighted by the arrow in the example). This realization contradicts the idea that $\mathrm{G}$ functions as an appoggiatura, and perhaps even suggests the retention of GMaj7 $\# 11$ from mm. 1-2 into the next two measures. This idea could also override B in favour of $\mathrm{G}$ as potential RT, a conception that was posited when considering the opening bass vamp. However, the melody's emphasis on B enables me to retain my initial hearing and analyze the pitch $\mathrm{G}_{3}$ as a non-specified chord tone-one that is nonetheless a member of the RS that is governing the passage. ${ }^{11}$ Therefore, the opening eight measures of "Kind Folk" consists of a single B minor chord, with $\mathrm{B}$ Aeolian as the governing RS. As we shall see, the prolonged emphasis on this single chord, as well as other factors discussed below, helps to prioritize B over other more localized tonics featured in subsequent sections of "Kind Folk."

Significant change begins in $\mathrm{m} .9$ (example 17 shows mm. 8-12). Contrast is achieved by an increase in attack density in the melody and an accelerated harmonic rhythm, where chords now change at a rate of one per bar; these features support hearing mm. 9-12 as a type of "continuation" of the opening eight measures..$^{32}$ Change at m. 9 is also achieved by the FMaj $\# \#^{\sharp 1}$ harmony and the addition of two new pitches-F and $\mathrm{C}$. Because jazz tunes tend to be structured in phrase-lengths that have four as a common denominator (four, eight, sixteen, thirty-two, as well as twelve [blues]), contrasting material beginning at $\mathrm{m} .9$ supports hearing $\mathrm{m} .8$ as a formal boundary and $\mathrm{m} .9$ as the start of a new phrase. Of course, because chord-root $F$ (m. 9) proceeds to chord-root $F^{\sharp}$ in the next measure, one could argue that $\mathrm{F}^{\mathrm{h}}$ is a momentarily altered member of B Aeolian (perhaps a chromatic lower neighbour between the fifth of

31 Following the most basic of modal practices, it could be possible for an accompanist to play any of the members of the RS when comping over mm. 3-4. Thus, in regards to Frisell's performance, I am designating $\mathrm{G}_{3}$ as a non-specified chord tone, as opposed to a non-chord tone. This pitch, which is the sixth over a B-rooted chord, is not specified in the chord symbol given on the lead sheet, but it is not analyzed as a performance error, since it is a member of the governing referential set.

32 William Caplin defines a continuation as "a medial intrathematic function that destabilizes the prevailing formal function by means of fragmentation, harmonic acceleration, faster surface rhythm, and harmonic sequence." It is in following this definition that I describe mm. 9-12 as a type of "continuation" of the opening eight measures. See Caplin 1998, 254. 
Bmin ${ }^{(\text {add9) }}$ and the root of $\mathrm{FH}^{\sharp} \mathrm{min} 7^{\mathrm{b5}}$ ). With $\mathrm{C}$ h retained across mm. 9-12, and the bass motion from F\# up to G, I hear the chord in $\mathrm{m}$. 10 as the less stable one, and its root as a less stable, chromatic passing tone between two more stable notes.

These changes support a shift of RS at mm. 9-12. The initial perfect-fourth leap between $\mathrm{B}_{3}$ and $\mathrm{E}_{4}(\mathrm{~mm} .8-9)$ is reminiscent of the $\mathrm{F}_{4} \rightarrow \mathrm{B}_{4}$ motion heard in $\mathrm{m}$. 1. Accordingly, this leap could suggest a shift to E as RT in mm. 9-12. The chords throughout these measures, however, do not substantiate such an interpretation. For instance, a chord-scale interpretation of FMaj; $\#^{11}$ supports F Lydian. ${ }^{33}$ However, because the most prominent melodic pitch in $\mathrm{m} .9$ is the sharp-eleventh-a dissonant note against the chord's root-F as RT is obscured. Despite this challenge, the arrival of CMaj7 in m. 11 extends the collection initially suggested by FMaj $\not^{\# 1}$. By prioritizing the chord in $\mathrm{m}$. 11 over that in m. 9, it is possible to interpret the melody as comprising the guide tones (the third and seventh) of CMaj7. The retention of these important chord tones across a relatively chromatic succession of harmonies encourages a sense of continuity, and is reminiscent of "Who Are You?," in which Wheeler retains the root and fifth of the tonic, A minor, across an analogous chromatic passage (refer to example 7). Further, the retention of pc $\mathrm{C}$ across all four chords within the phrase helps to promote its significance. In short, $\mathrm{C}$ can be understood as RT in mm. 9-12, and C Ionian as its corresponding RS.

With C functioning as RT in $\mathrm{mm} .9-12$, a tonic shift has occurred, moving

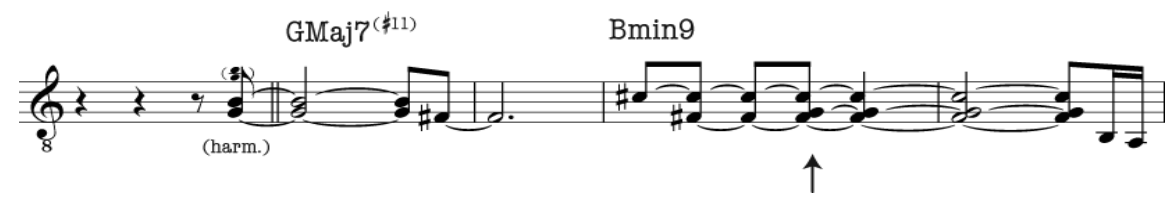

Example 16: Bill Frisell's performance of the opening of "Kind Folk" ( 0:07-0:14)

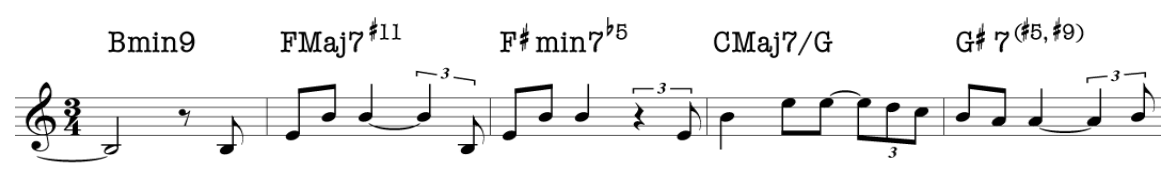

Example 17: Transitional passage in A Section (mm. 8-12)

up by a semitone from the opening phrase's RT B (mm. 1-8). This semitonal rise continues in phrase three-one that is initiated by the tonicizing $\mathrm{C} \#$-chord in $\mathrm{m}$. 13. However, until m. 12's chord resolves, it is possible to retain the governing RS throughout the four-measure continuation phrase, and to analyze $\mathrm{G}_{7}\left(\#_{5}, \#_{9}\right)$ as a chromatically altered member of $\mathrm{C}$ Ionian. This is possible since the tonic chord, consisting of the root, third, and seventh, is sustained into the

33 This scale is also supported by the chord in m. 11, CMaj7/G, since all of its chord members are included in the F Lydian scale. 


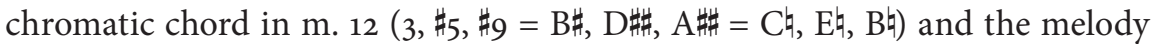
notes in this measure are both members of $C$ Ionian ( $\left.\# 9,{ }^{b} 9=B^{\natural}, A^{A}\right)$. As a result, these apparently "altered" pitches make the measure more consistent with the passage's governing set. 34 This interpretation is supported by an improvisation by Wheeler discussed below (example 19).

To summarize the RS continuity, example 18 illustrates the pc-content of the chords from mm. 9-12. In this representation, non-members of C Ionian appear in grey. Support for RT C is highlighted in the example with boxes, showing that the tonic chord, $\langle\mathrm{C}, \mathrm{E}, \mathrm{B}\rangle$, is a subset in all but one of the chords; the remaining chord contains only its root and third, $<\mathrm{C}, \mathrm{E}\rangle$. It is striking how, in m. 12, the RT becomes enharmonically reinterpreted as the leading tone to $C \#$, which, as will be shown, is the RT of the following phrase. In short, the reinterpretation makes the semitone relationship between adjacent tonics explicit.

To further support this passage in C Ionian, let us consider Wheeler's improvisation. Example 19 shows that in one chorus he uses exclusively "white key" pcs, and emphasizes the root, third, and fifth of $\mathrm{C}$ major, making the music much more consistent with $\mathrm{C}$ Ionian than with the chord being tonicized in m. 13. In m. 12, it appears that Wheeler's improvisational choices reflect and support the RS that is most prominent at that moment rather than directed towards any possible subsequent sets. In short, until the $\mathrm{G}_{\sharp}\left({ }^{\left(\#_{5}, \#_{9}\right)}\right.$ chord in $\mathrm{m}$. 12 resolves, it is possible to hear it as an altered subset of $C$ Ionian.

The melody of mm. 13-16 transposes mm. 1-4 down by a minor third ${ }^{35}$-an interval that has significance in the tune's B Section..$^{36}$ As a result, one might assume a similar transposition of governing RT and RS, resulting in G\# Aeolian. The chords in mm. 14 and 16, however, do not support this scale, nor is it maintained in the musicians' improvisations. Examples 20a-b show how both Wheeler and Konitz maintain a collection that includes A A, and not A\#. Therefore, given the melodic transposition described above, an alternate possibility for RS could be $G \#$ Phrygian. However, the resolution of $G \sharp 7$ to $C \sharp m_{i n}{ }^{(a d d 9)}$ between $\mathrm{mm} .12-13$ is especially noteworthy, given that the former is the only dominant chord used in the entire A Section; consequently, $C \sharp$ receives significant emphasis. Further, the progression $\mathrm{C} \sharp \min ^{(\text {addg) }} \rightarrow$ AMaj $7 \sharp^{11}$ is borrowed from the tune's opening-i.e., a transposition of Bmin ${ }^{(\text {add } 9)} \rightarrow$ GMaj $\mathbb{Z}^{11}$. Accordingly, my preference is to assign $\mathrm{C}_{\sharp}$ as the governing $\mathrm{RT}$ in $\mathrm{mm} .13^{-16}$, and $\mathrm{C} \#$ Aeolian as its corresponding RS. 37

$34 \mathrm{GH}^{\sharp 5},{ }^{\sharp}, 9$ could also be heard as a tritone substitute for D7, which would be V7/V in C Ionian. In this case, non-RS members of the tritone substitute chord can be understood as semitone displacements-or momentary alterations-of the more stable RS members to which they would traditionally resolve. Specifically, both $G \#$ and $F \#$, enharmonically reinterpreted as the root and seventh of $A^{b} 7^{\sharp 5}, \sharp^{*}$, would be displacements of $\mathrm{G}^{\natural}-$ a member of $\mathrm{C}$ Ionian. This idea was suggested in my analysis of Wheeler's "Who Are You?," in example 6.

35 The transpositional relationship corresponds to that between $\mathrm{G}_{4} 4(\mathrm{~m} .13)$ and $\mathrm{B} 4$ (m. 1). The melody that begins in $\mathrm{m} .13$ excludes the perfect-fourth leap that initiates the opening melody.

36 The melodic transposition heard between mm. 1-4 and mm. 13-16 is a descending minor third; what is heard between the A Section and the B Section is an ascending minor third.

37 The final eighth note in Konitz's solo can be analyzed as an anticipation of the RS in the succeeding measure $\left(A^{\sharp}=B^{b}\right)$. 

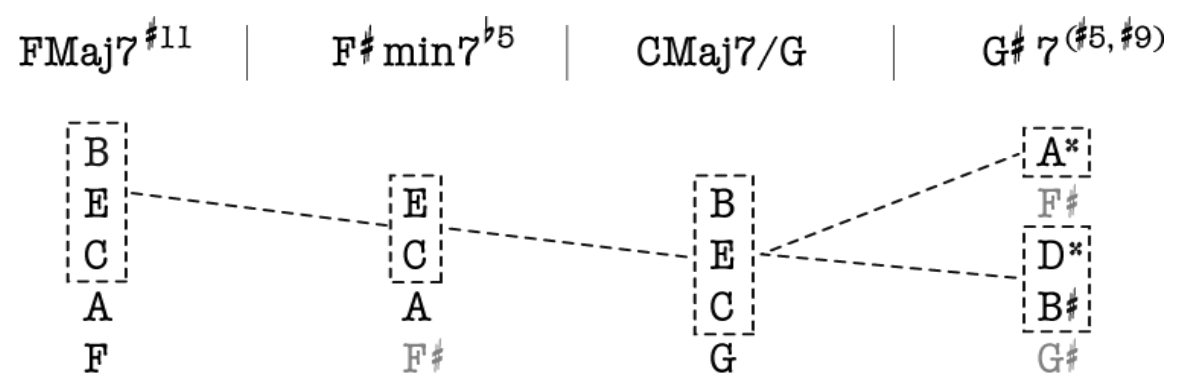

Example 18: RT C, and C Ionian, supported across chord series of mm. 9-12

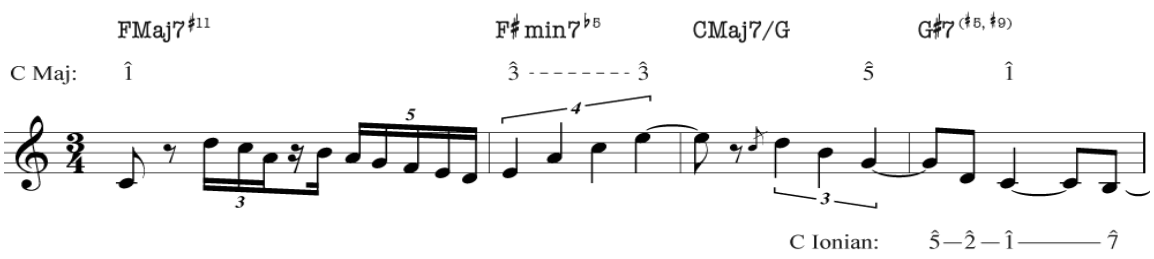

Example 19: Kenny Wheeler, solo on "Kind Folk" (mm. 9-12, 3:52-3:58)

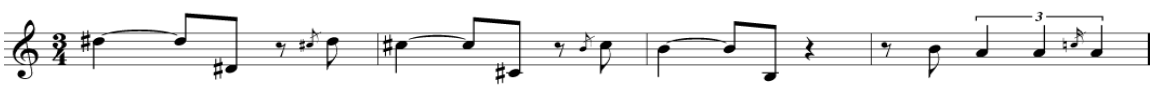

Example 2oa: Kenny Wheeler, solo on "Kind Folk" (mm. 13-16, 3:09-3:15)

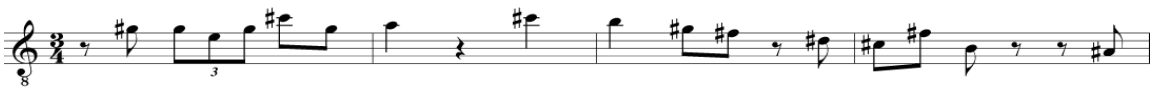

Example 2ob: Lee Konitz, solo on "Kind Folk" (mm. 13-16, 5:37-5:43)

The shift to RT C\# continues the rising semitone tonic-transposition recently established between mm. 1-8 and mm. 9-12. As a result, I can understand the A Section of "Kind Folk" to be organized under the following RTs: $B \rightarrow C \rightarrow C \#$, represented in example 21. Despite these shifts, however, an overarching continuity is achieved throughout the A Section: specifically, pc B is emphasized throughout the first sixteen measures. This emphasis is most explicit in the opening eight measures. But in the melody of mm. 9-12, pc B is accented by leap, register, and duration, and in $\mathrm{mm} .15-16$ by duration and contour. It also has structural prominence as a guide tone (seventh) of both of the A Section's subsequent RTs, $\mathrm{C}$ and $\mathrm{C} \#$.

The B Section of "Kind Folk" (mm. 17-32) transposes the A Section almost exactly. The melody is exactly transposed up a minor third, recalling the downward minor-third transposition in mm. 13-16. However, the chords are not all transposed the same way. For instance, in $\mathrm{mm} .17-24$, rather than the expected $\mathrm{B}^{\mathrm{b}} \mathrm{Maj} \sharp^{\sharp 1} \rightarrow \mathrm{Dmin}^{(\mathrm{add} 9)}$, a direct transposition of the chord series used in the opening eight measures, the lead sheet includes an additional chord; the chord progression that initiates the B Section is $\mathrm{B}^{\mathrm{b}} \mathrm{Maj} 7^{11} \rightarrow \mathrm{Amin}^{(11)} \rightarrow \mathrm{Dmin}^{(11)}$. 

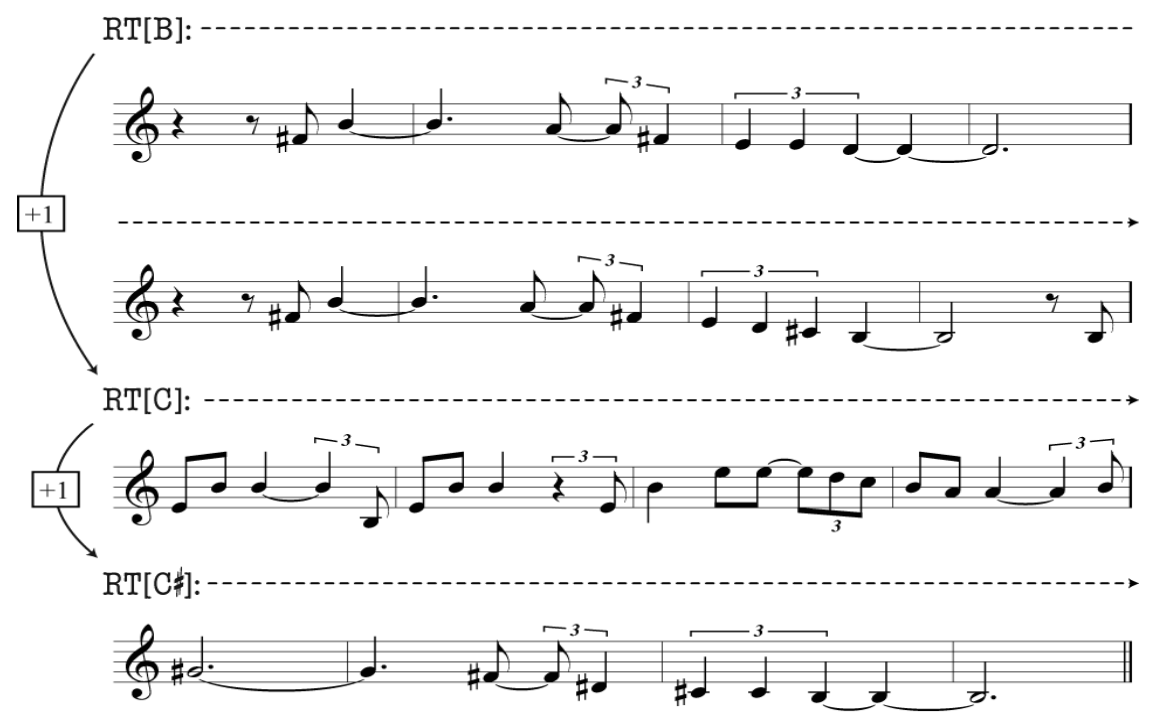

Example 21: RT shifts in A Section of "Kind Folk"

Further, the harmonic rhythm increases: what was one chord every two measures in mm. 1-8 is now one harmony per measure. As a result, this three-chord progression is repeated nearly three times in its entirety during the eight-measure melodic group.

This root succession now includes motion by fifth, which helps to draw attention towards D. Following from the aforementioned transposition, and supported by this root succession, D is understood as RT in mm. 17-24. The root succession between $B^{b}$ Majj $\sharp 11 \rightarrow$ Amin $7^{(11)}$ transfers the $b \hat{6} \rightarrow \hat{5}$ melodic motion, initially suggested as an inner voice in $\mathrm{mm}$. 1-8 (see example 15), to the bass, making it a more explicit part of the outer-voice structure. Also noteworthy is that this interpolated chord does not disturb the identity of the referential set, since no non-RS members occur throughout the series. Example 22 shows the pc content of the three-chord succession; it contains all the elements of D Aeolian. This set is also supported in Konitz's improvisation over the opening eight measures of Section B, as shown in example 23. As is the case with the underlying chord succession, the scale degrees identify that Konitz's solo accounts for every RS member. In short, I understand the opening eight measures of each section governed by minor-third-related referential sets: B Aeolian and D Aeolian, respectively.

Despite the shift produced by transposing mm. 1-8 in mm. 17-24, continuity is maintained in the specific sense that $\mathrm{mm}$. 17-24's RT continues the semitone rise heard in mm. 1-16-i.e., $\mathrm{B} \rightarrow \mathrm{C} \rightarrow \mathrm{C} \# \rightarrow \mathrm{D}$. Because the entire B Section is a transposition of the A Section, RT Eb follows RT D in the B Section's continuation phrase (mm. 25-28), which is then followed by the final RT of the tune, E. In other words, the overarching organization of "Kind Folk" is based on the following series of RTs: $\mathrm{B} \rightarrow \mathrm{C} \rightarrow \mathrm{C} \sharp \mathrm{D} \rightarrow \mathrm{E}^{b} \rightarrow \mathrm{E}$ (example 24 contains 


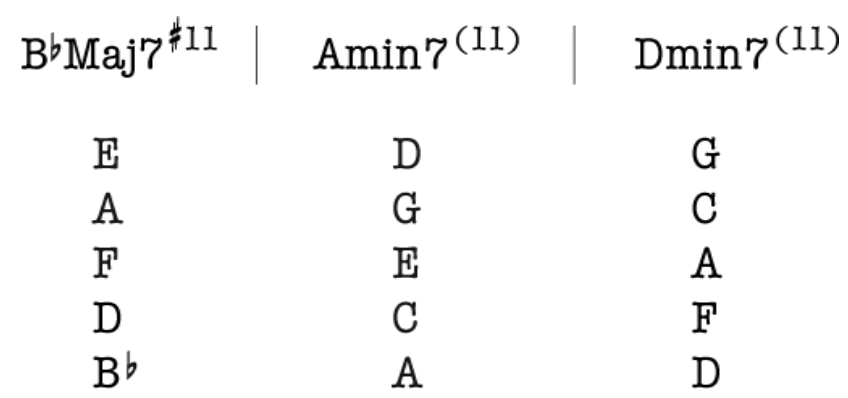

Example 22: D Aeolian expressed across chord series used in mm. 17-24

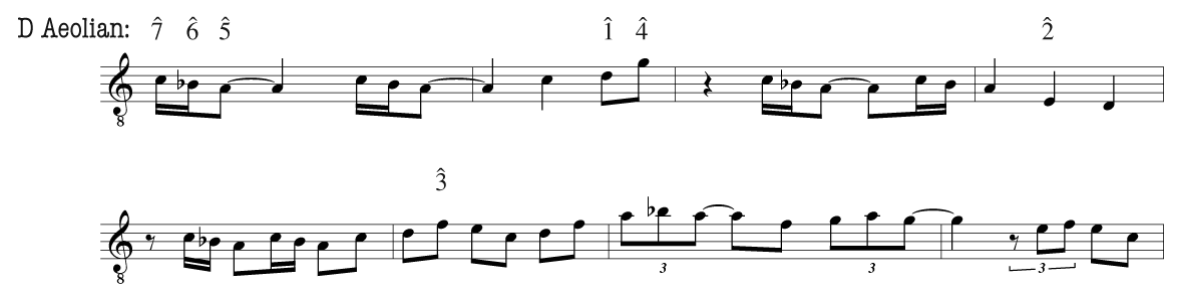

Example 23: Lee Konitz, solo on "Kind Folk" (mm. 17-24, 4:53-5:06)

a transpositional network representation of the series). Each node in the example's network represents the RTs that govern the tune's respective sections and contains the semitone rise between consecutive RTs $(+1)$. The curved line connecting the two nodes depicts the minor-third relationship between the two sections of the tune (m3), while the broken diagonal line indicates that the semitone rise $(+1)$ continues from the end of Section A into the beginning of Section B.

Also of note is the pattern underlying the series of modes of the governing RSs: the minor-mode sets that border each section are interspersed with a major-mode set in the continuation phrases. Accordingly, I understand the majormode RTs of the continuation phrases to be less important than the minormode ones, functioning as large-scale chromatic passing formations. (That is, $\mathrm{B}$ and $\mathrm{C} \#$ are connected by $\mathrm{C}$ in the $\mathrm{A}$ Section, and $\mathrm{D}$ and $\mathrm{E}$ are connected by $\mathrm{E}^{b}$ in the B Section.) In sum, I conceive "Kind Folk" as a whole to be organized according to a B minor tetrachord, which prioritizes the tune's opening RT above all others. The diagram in example 25 illustrates how the RTs of the minormode sets share the same transpositional relationships as a minor tetrachord.

Let me offer a further observation about the melody that supports my reading of the importance of B Aeolian. Because the melody in mm.13-16 is a transposition of the melody in mm. 1-4, and the melody in mm. 29-32 is a transposition of that in mm. 17-20, I associate the opening and closing measures of each section as a result of their direct melodic transposition. Moreover, because the melody in mm. 17-32 is a minor third transposition up from mm. 1-16, and mm. 13-16 are transposed down a minor third from $\mathrm{mm} .1-4$, then the last four 


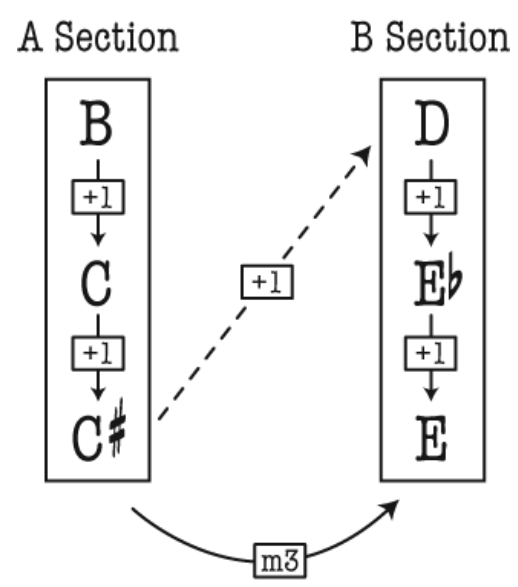

Example 24: Network representation of RTs governing "Kind Folk"

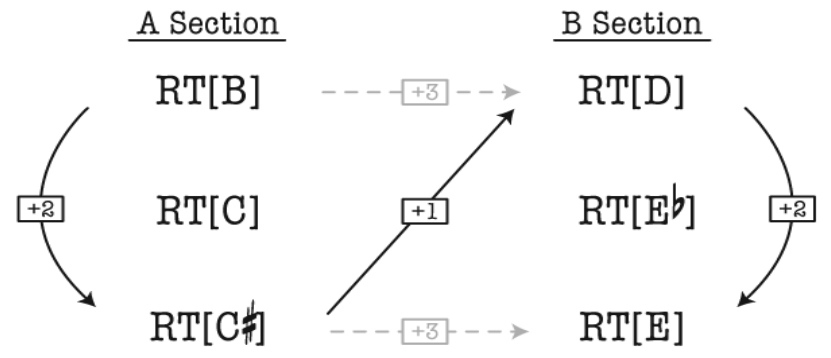

RTs:

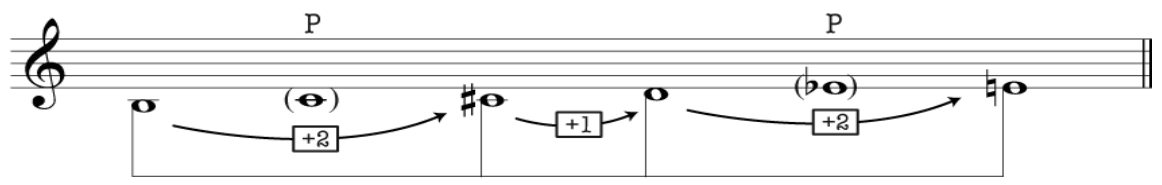

B minor tetrachord

Example 25: RSs governing "Kind Folk"; RTs supporting B minor tetrachord

measures of the tune's melody (mm. 29-32) equal the first four measures (mm. 1-4). In short, "Kind Folk" opens and closes with the same melody.

Final support for RT B comes at the end of the tune. Each of the three recordings noted at the outset concludes with a return to the opening vamp. Further, all three vamps are prolonged over multiple measures and end on the second of the two dyads, $\angle B, F \sharp>$, which we can now intuit as the root and fifth of the RT chord.

The preceding article shows how an analytical approach that begins with the melody can promote an understanding of Wheeler's music, and in particular his chord successions, beyond a surface-level chord-scale correspondence. Of course, many contemporary jazz tunes feature non-diatonic chord successions 
that do not emphasize harmonic continuity, and so often encourage a chordscale approach to their realization and improvisation. This, in effect, asks the player to concentrate on what notes to play on each change, rather than on continuities across multiple changes. Accordingly, current analyses of these types of chord successions tend to focus primarily on identifying a scale for each chord, and not on keys or harmonic progression $3^{8}$ However, by considering Wheeler's music, as well as potentially that of other contemporary jazz composers, from the perspective presented in this article, characteristically nonfunctional chord successions can become more comprehensible. Such a perspective is achieved by encouraging the retention of the single most-referential pc set through seemingly unrelated harmonic events, and, where necessary, chromatically altering members that do not, otherwise, change the perception of an overarching (referential) tonic. As a result, it is possible to identify and describe deviations from a given RS as they relate to the underlying chord changes while still retaining a global sense of tonic. As opposed to more common jazz analyses that consider the melody only through its relationship with an underlying chord, prioritization of the melody can help to provide both a productive and practical understanding of pitch-class content.

\section{REFERENCES}

Arthurs, Daniel J. 2011. "Reconstructing Tonal Principles in the Music of Brad Mehldau." PhD diss., Indiana University.

Bambarger, Bradley. 1997. "Wheeler's Luminous 'Angel," Billboard 109 (6): 1.

Caplin, William E. 1998. Classical Form: A Theory of Formal Functions for the

Instrumental Music of Haydn, Mozart, and Beethoven. New York: Oxford University Press.

DeVeaux, Scott and Gary Giddins. 2009. Jazz. New York: W. W. Norton.

Eyles, John. 2003. "Kenny Wheeler, Ennio Morricone and Wayne Shorter." All About Jazz. http://www.allaboutjazz.com/php/article.php?id=993.

Gridley, Mark C. 2009. Jazz Styles: History and Analysis. 1oth ed. Upper Saddle River, NJ: Pearson Prentice Hall.

Hum, Peter. 2011. "Gentle Giant: Kenny Wheeler Profiled." Ottawa Citizen, 1 July. http://blogs.ottawacitizen.com/2011/07/o1/ gentle-giant-kenny-wheeler-profiled/.

Julien, Patricia A. 2003. "The Structural Function of Harmonic Relations in Wayne Shorter's Early Compositions: 1959-1963." PhD diss., University of Maryland.

Kopp, David. 2002. Chromatic Transformations in Nineteenth-Century Music. New York: Cambridge University Press.

Martin, Henry. 1996a. Charlie Parker and Thematic Improvisation. Lanham, MD: Scarecrow.

-1996b. “Jazz Theory: An Overview.” Annual Review of Jazz Studies 8:1-17. Martin, Henry, and Keith Waters. 2012. Jazz: The First 100 Years. 3rd ed. Belmont, CA: Thomson Shirmer.

38 See, for instance, Daniel Arthurs's example 4.7, which includes a chord/scale analysis of the tune "Unrequited" (1998 Brad Mehldau), 2011, 115-16. 
Rinzler, Paul. 1999. "The Quartal and Pentatonic Harmony of McCoy Tyner." Annual Review of Jazz Studies 10:35-87.

Russell, George. 1959. The Lydian-Chromatic Concept of Tonal Organization for Improvisation. New York: Concept.

Santa, Matthew. 2003. "Nonatonic Progressions in the Music of John Coltrane." Annual Review of Jazz Studies 13:13-25.

Tanner, Paul, David W. Megill, and Maurice Gerow. 2009. Jazz. 11th ed. New York: McGraw-Hill.

Tymoczko, Dimitri. 2011. A Geometry of Music: Harmony and Counterpoint in the Extended Common Practice. New York: Oxford University Press.

Waters, Keith, and J. Kent Williams. 2010. "Modeling Diatonic, Acoustic, Hexatonic, and Octatonic Harmonies and Progressions in Two- and ThreeDimensional Pitch Spaces; or Jazz Harmony after 1960." Music Theory Online 16 (3). http://www.mtosmt.org/issues/mto.10.16.3/mto.10.16.3.waters_ williams.html.

Yamaguchi, Masaya. 2002. "A Creative Approach to Multi-Tonic Changes: Beyond Coltrane's Harmonic Formula." Annual Review of Jazz Studies 12:147-67.

\title{
Discography
}

Azimuth. 1985. "Who Are You?" Composed by Kenny Wheeler and Jane White. Produced by Manfred Eicher. Azimuth '85. ECM Records ECM 1298.

Evans, Bill. 1976. "Sweet Dulcinea Blue." Composed by Kenny Wheeler. Produced by Helen Keane. Quintessence. Fantasy F-9529.

Konitz, Lee, and the Kenny Wheeler Quartet. 200o. "Kind Folk." Composed by Kenny Wheeler. Produced by Volker Dueck. Live at Birdland Neuburg. Double Moon Records DMCHR 71014.

Wheeler, Kenny. 1976. "Quiso." Composed by Kenny Wheeler. Producer unknown. 1976. Just a Memory Records JAS 9506-2.

—_.1990. "Kind Folk." Composed by Kenny Wheeler. Produced by Manfred Eicher. Music for Large and Small Ensembles. ECM Records. ECM 843152.

— 1996. "Kind Folk." Composed by Kenny Wheeler. Produced by Manfred Eicher. Angel Song. ECM Records. ECM 1607.

Wheeler, Kenny, and Brian Dickinson. 1999. "Kind Folk." Composed by Kenny Wheeler. Produced by Andrew Hurlbut. Still Waters. Hornblower HR99105.

\begin{abstract}
The article examines some representative tunes by the notable Canadian jazz trumpeter and composer Kenny Wheeler. Though rooted in traditional jazz practices, Wheeler's own compositions often deviate from tradition. For instance, his chord successions are sometimes highly chromatic and often non-diatonic. Further, he often excludes Mm7 chords, which diminishes the sense of traditional functionality. Yet his melodies tend to promote longer-reaching relationships that prioritize certain pitchclass collections over others. In contrast to the more traditional chord-scale approach commonly used to analyze jazz tunes, the prime goal of the article will be to show how
\end{abstract}


continuity across less-conventional chord successions is conceivable when taking a top-down analytical approach-that is, when prioritizing the melody.

\section{RÉSUMÉ}

Cet article examine quelques pièces représentatives de l'œuvre du trompettiste et compositeur canadien Kenny Wheeler. Bien que son travail soit ancré dans la tradition jazz, les compositions de Wheeler s'en distancient souvent. Ses enchaînements d'accords, par exemple, sont parfois remarquablement chromatiques et souvent non-diatoniques. De plus, il élimine souvent les accords de septième majeurs et mineurs, ce qui diminue le sens de la fonction harmonique traditionnelle. Toutefois, ses mélodies tendent à favoriser des relations de plus longue portée en mettant l'emphase sur certains ensembles de hauteurs plus que sur d'autres. En contraste avec l'approche traditionnelle de l'analyse harmonique des pièces de jazz, l'objectif principal de cet article est de montrer qu'il est possible de concevoir une continuité au sein d'enchaînements harmoniques moins conventionnels, lorsque l'on adopte une approche analytique allant du haut vers le bas, et qui en fait donne priorité à la mélodie. 